\title{
Precipitation of angle closure
}

\author{
R. MAPSTONE \\ St. Paul's Eye Hospital, Old Hall Street, Liverpool, $L_{3}{ }_{9} P F$
}

Previous papers (Mapstone, I974a, b) have shown that angle closure (AC) is primarily a result of the activity of the autonomic nervous system, but that no direct relationship exists between the size of the pupil blocking force (pbf) and AC. The purpose of this paper is to investigate the anterior segment changes that produce $A C$ and to devise a rational method for its precipitation.

\section{Material and methods}

(I) Fifty eyes from 44 patients, six of whom had sub-acute closed-angle glaucoma and 38 closedangle glaucoma in the contralateral eye were provoked in one of two ways detailed below. Patients with chronic closed-angle glaucoma or in whom closed-angle glaucoma was secondary were excluded.

(a) At zero hours intraocular pressure was measured, an anterior segment photograph was taken, and pilocarpine drops 2 per cent. and phenylephrine drops 10 per cent. were instilled three times at $\mathrm{I}$-min. intervals. Subsequently intraocular pressure and anterior segment photographs were taken at approximately $\frac{1}{2}$-hr intervals; at the same time an additional drop of phenylephrine was instilled. If after $2 \mathrm{hrs}$ intraocular pressure had not risen significantly, then a further pilocarpine 2 per cent. three times at $\mathrm{I}$-min. intervals was instilled. As soon as intraocular pressure increased with a gonioscopically closed angle, intravenous Diamox $500 \mathrm{mg}$., pilocarpine drops 2 per cent. and thymoxamine drops 0.5 per cent. were given-the drops at 15 -min. intervals. The slides were subsequently projected, pupil diameters $(\mathrm{P})$ and corneal diameters $(\mathrm{C})$ were measured in the horizontal meridian, and $\mathrm{P} / \mathrm{C}$ ratios were calculated. 25 eyes from $2 \mathrm{I}$ patients were provoked in this fashion. In addition, six of the patients were given Diamox Sustets $500 \mathrm{mg}$. I $\mathrm{hr}$ before provocation commenced.

(b) At zero hours intraocular pressure was measured, an anterior segment photograph was taken, and pilocarpine drops 2 per cent. were instilled three times at $\mathrm{I}$-min. intervals. After a variable interval (20 min. to $3 \mathrm{hrs}$ ) phenylephrine drops ro per cent. three times were instilled. Intraocular pressure and anterior segment photographs were taken and thereafter at approximately $\frac{1}{2}$-hr intervals, at the same time an additional drop of phenylephrine was instilled. If, $2 \mathrm{hrs}$ after the first phenylephrine, intraocular pressure had not risen significantly, then pilocarpine drops 2 per cent. three times at $\mathrm{I}$-min. intervals was given. As soon as intraocular pressure increased with a gonioscopically closed angle, the patient was treated as described in (a) above. Slides were subsequently projected and $\mathrm{P} / \mathrm{C}$ ratios calculated. 25 eyes from 23 patients were provoked in this fashion. Three of the patients had Diamox Sustets $500 \mathrm{mg}$. I hr before provocation commenced.

(2) 28 eyes from 28 patients with narrow angles and no suggestive history were provoked as in $\mathbf{I}(a)$.

(3) Ten eyes from ten patients who had closed-angle glaucoma in the contralateral eye were dilated with phenylephrine drops Io per cent. three times at I-min. intervals. Intraocular pressure was measured and anterior segment photographs taken at approximately $\frac{1}{2}$-hr intervals. The effect of dilatation is discussed in a previous paper (Mapstone, 1974). Here the effect of producing miosis with thymoxamine drops 0.5 per cent. three times at $\mathrm{I}$-min. intervals is recorded. Slides were subsequently projected and $\mathrm{P} / \mathrm{C}$ ratios calculated. 
Simultaneous Pilocarpine and Phenylephrine
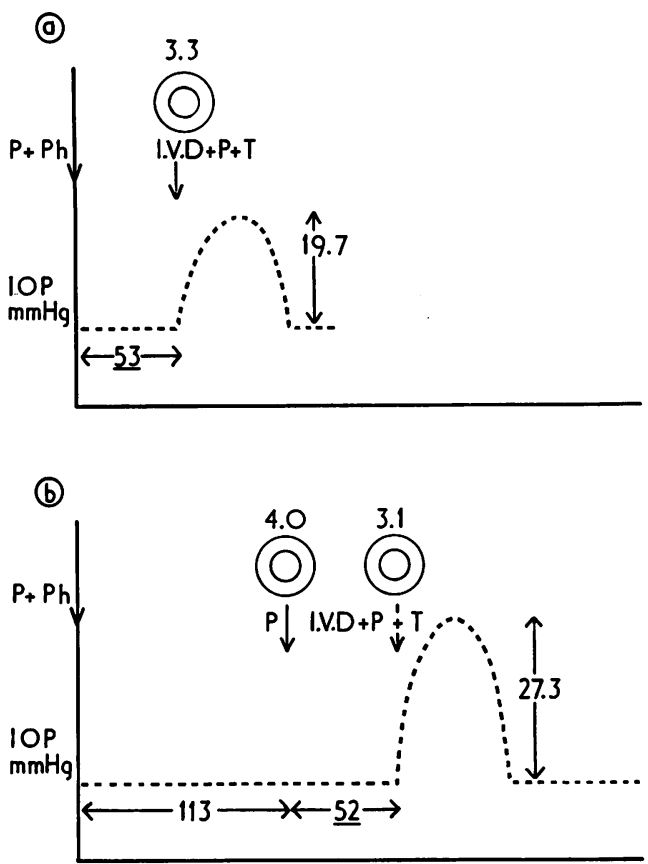

Time (minutes)

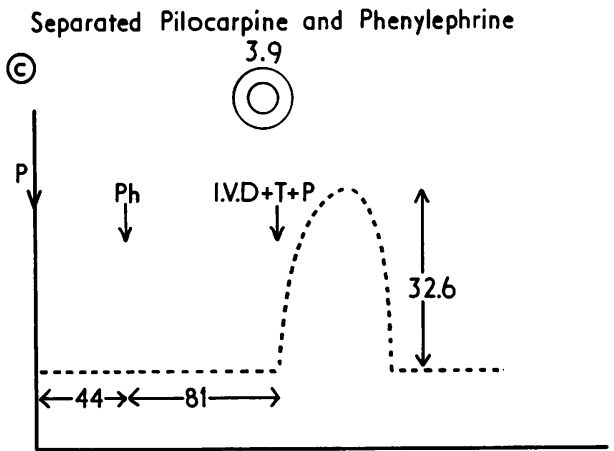

(d)

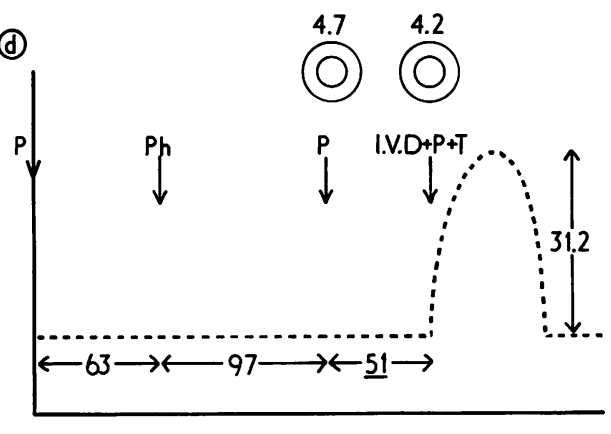

Time(minutes)

FIG. I Mean statistics of eyes provoked to angle-closure by phenylephrine and pilocarpine

(a) Simultaneous instillation of phenvlephrine and pilocarpine

(b) Simultaneous instillation of phenylephrine and pilocarpine; additional pilocarpine needed to provoke angle closure (c) Separated instillation of phenylephrine and pilocarpine

(d) Separated instillation of phenylephrine and pilocarpine; additional pilocarpine needed to provoke angle closure

Pupil diameters $(P / C$ ratios $\times 10)$ at instillation of additional pilocarpine and angle closure are shown. For simplicity all instillations of phenylephrine are not shown.

$$
P=\text { pilocarpine } \quad P h=\text { phenylephrine } \quad T=\text { thymoxamine } \quad I V D=\text { intravenous diamox }
$$

(4) Ten eyes from ten patients who had closed-angle glaucoma in the contralateral eye were dilated with cyclopentolate drops I per cent. and thymoxamine drops 0.5 per cent. three times at I-min. intervals. Intraocular pressure was measured and anterior segment photographs taken at approximately $\frac{1}{2}$-hr intervals. The effect of dilatation is discussed in a previous paper (Mapstone, 1974). Here the effect of miosing the pupil with pilocarpine drops 2 per cent. $\frac{1}{2}$-hrly is recorded. If intraocular pressure increased, treatment was as in $\mathbf{I}(a)$, slides were subsequently projected and $\mathrm{P} / \mathrm{C}$ ratios calculated.

\section{Results}

(I) (a) Of the 25 eyes provoked by the simultaneous instillation of pilocarpine and phenylephrine, 2 I developed closed-angle glaucoma; eighteen required no further pilocarpine, and three did. 
(b) Of the 25 eyes provoked by the separate instillation of pilocarpine and phenylephrine, twenty developed closed-angle glaucoma; eight required no further pilocarpine, and twelve did.

The statistics relating to these four provocation groups are collected under the following headings in the Table.

(i) Mean time interval between start of provocative test and rise in intraocular pressure.

(ii) Mean time interval between instillation of pilocarpine and phenylephrine.

(iii) Mean time interval between instillation of first and second pilocarpine.

(iv) Mean time interval between instillation of second pilocarpine and rise in intraocular pressure.

(v) Mean rate of rise in intraocular pressure.

(vi) Mean increase in intraocular pressure.

(vii) Mean $\mathrm{P} / \mathrm{C}$ ratio at onset of rise in intraocular pressure.

(viii) Mean $\mathrm{P} / \mathrm{C}$ ratio at instillation of second pilocarpine.

(ix) Number of patients not controlled by hypotensive treatment and requiring peripheral iridectomy.

Table Development of closed-angle glaucoma in four groups of eyes provoked by simultaneous or separate administration of pilocarpine and phenylephrine, with and without additional pilocarpine

\begin{tabular}{|c|c|c|c|c|}
\hline \multirow{2}{*}{$\begin{array}{l}\text { Administration of drugs } \\
\text { (no. of eyes) }\end{array}$} & \multicolumn{2}{|c|}{$\begin{array}{l}\text { Pilocarpine and phenylephrine } \\
\text { simultaneously (25) }\end{array}$} & \multicolumn{2}{|c|}{$\begin{array}{l}\text { Pilocarpine and phenylephrine } \\
\text { separately }(25)\end{array}$} \\
\hline & 21 & & 20 & \\
\hline Additional pilocarpine & No (18) & Yes (3) & No (8) & Yes (12) \\
\hline $\begin{array}{l}\text { (i) Time (min.) between } \\
\text { start of test and rise in pressure }\end{array}$ & $\begin{array}{l}54 \\
\left(25^{-1} I_{5}\right)\end{array}$ & $\begin{array}{l}165 \\
\left(145^{-1} 85\right)\end{array}$ & $\begin{array}{l}125 \\
(70-240)\end{array}$ & $\begin{array}{l}211 \\
(130-310)\end{array}$ \\
\hline $\begin{array}{l}\text { (ii) Time ( } \mathrm{min} .) \text { between } \\
\text { instillations }\end{array}$ & o & o & $\begin{array}{l}44 \\
(20-75)\end{array}$ & $\begin{array}{l}63 \\
(30-170)\end{array}$ \\
\hline $\begin{array}{l}\text { (iii) Time (min.) between first } \\
\text { and second pilocarpine }\end{array}$ & - & $\begin{array}{l}\text { I } 13 \\
(109-120)\end{array}$ & - & $\begin{array}{l}160 \\
(90-245)\end{array}$ \\
\hline $\begin{array}{l}\text { (iv) Time (min.) between } \\
\text { second pilocarpine and rise } \\
\text { in pressure }\end{array}$ & - & $\begin{array}{l}5^{2} \\
\left(3^{6}-75\right)\end{array}$ & - & $\begin{array}{l}51 \\
(18-95)\end{array}$ \\
\hline $\begin{array}{l}\text { (v) Rate of rise in pressure } \\
(\mathrm{mm} . \mathrm{Hg} \text { in min.) }\end{array}$ & $\begin{array}{l}1 \mathrm{~mm} . \mathrm{Hg} \text { in } 3 \cdot 9 \\
(1 \cdot 2 \text { to } 6)\end{array}$ & $\begin{array}{l}\mathrm{Imm} . \mathrm{Hg} \text { in } 2 \cdot \mathrm{I} \\
\text { (I to } 3 \cdot 8 \text { ) }\end{array}$ & $\begin{array}{l}\mathrm{Imm} . \mathrm{Hg} \text { in } 2 \cdot 5 \\
\text { ( } \mathrm{m} \text { to } 6 \text { ) }\end{array}$ & $\begin{array}{l}1 \mathrm{~mm} . \mathrm{Hg} \text { in } 2 \cdot 2 \\
(1 \cdot 3 \text { to } 6)\end{array}$ \\
\hline $\begin{array}{l}\text { (vi) Increase in pressure } \\
(\mathrm{mm} . \mathrm{Hg})\end{array}$ & $\begin{array}{l}19 \cdot 7 \\
(8 \text { to } 48)\end{array}$ & $\begin{array}{l}27 \cdot 3 \\
(\text { II to } 4 I)\end{array}$ & $\begin{array}{l}32 \cdot 6 \\
(10 \text { to } 42)\end{array}$ & $\begin{array}{l}3 \mathrm{I} \cdot 2 \\
(\mathrm{I} 9 \text { to } 44)\end{array}$ \\
\hline $\begin{array}{l}\text { (vii) } \mathrm{P} / \mathrm{G} \text { ratio at onset } \\
\text { of rise in pressure }\end{array}$ & $\begin{array}{l}0.33 \\
(0 \cdot 24-0 \cdot 49)\end{array}$ & $\begin{array}{l}0 \cdot 31 \\
(0 \cdot 19-0 \cdot 4 I)\end{array}$ & $\begin{array}{l}0 \cdot 39 \\
(0 \cdot 32-0 \cdot 55)\end{array}$ & $\begin{array}{l}0 \cdot 4^{2} \\
\left(0 \cdot 3^{2-0} \cdot 57\right)\end{array}$ \\
\hline $\begin{array}{l}\text { (viii) } \mathrm{P} / \mathrm{C} \text { ratio at second } \\
\text { instillation of pilocarpine }\end{array}$ & - & $\begin{array}{l}0.4 \\
(0 \cdot 25-0 \cdot 49)\end{array}$ & - & $\begin{array}{l}0 \cdot 47 \\
(0 \cdot 38-0 \cdot 65)\end{array}$ \\
\hline $\begin{array}{l}\text { (ix) No. of patients } \\
\text { requiring iridectomy }\end{array}$ & 2 & I & 7 & 5 \\
\hline
\end{tabular}


The results are summarized in Fig. I for each group. A typical sequence from each group is illustrated in Figs 2, 3, 4, and 5 .
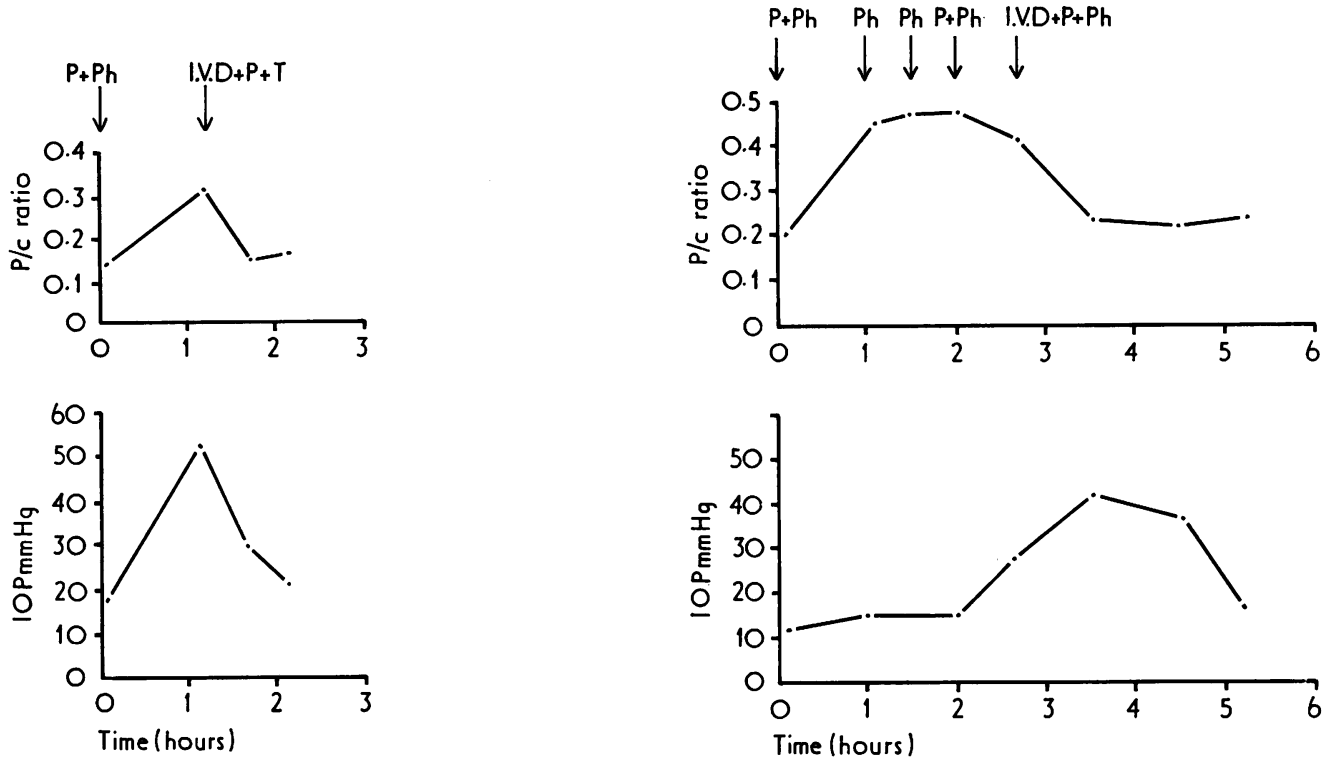

FIG. 2 Precipitation of angle closure by simultaneous instillation of phenylephrine and pilocarpine. No additional pilocarpine
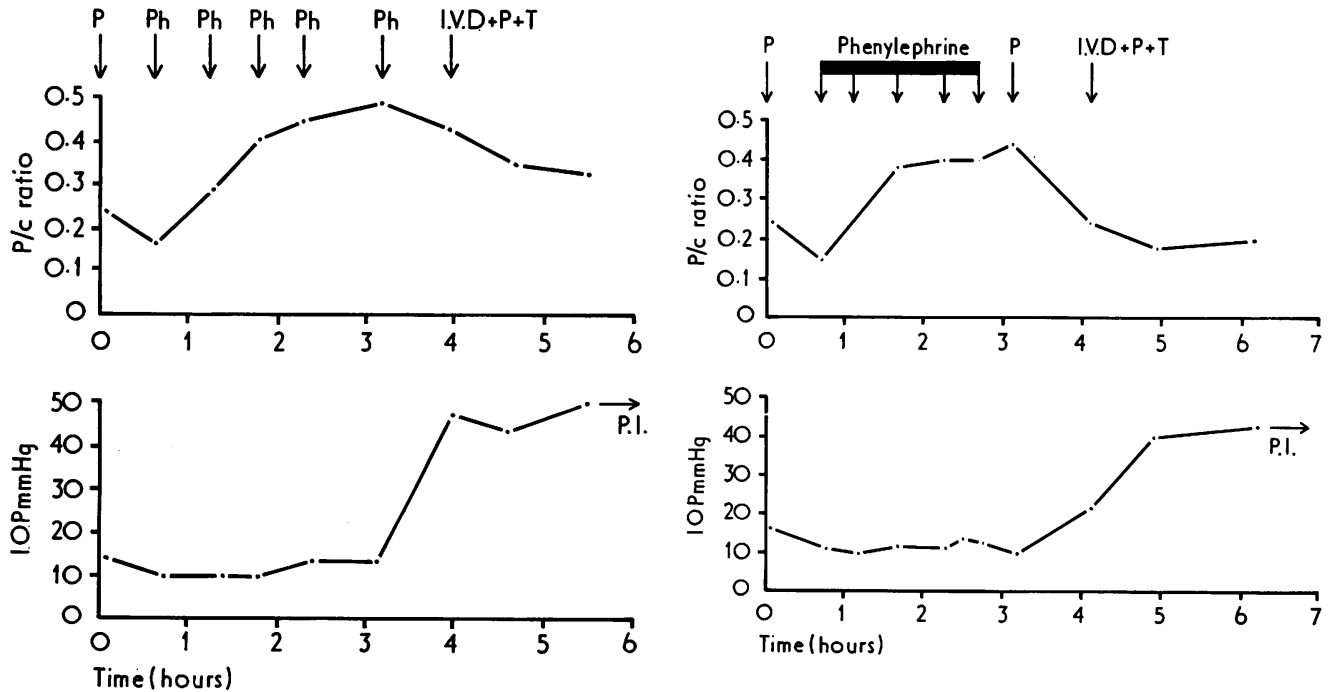

FIG. 4 Precipitation of angle closure by separate instillation of pilocarpine and phenylephrine. No additional pilocarpine. $\quad P I=$ Peripheral iridectomy

FIG. 5 Precipitation of angle closure by separate instillation of pilocarpine and phenylephrine. Additional pilocarpine necessary to provoke angle closure. $P I=$ peripheral iridectomy

FIG. 3 Precipitation of angle closure by simultaneous instillation of phenylephrine and pilocarpine. Additional pilocarpine necessary to provoke angle closure 
A histogram of the $\mathrm{P} / \mathrm{G}$ ratios at which intraocular pressure began to increase is shown in Fig. 6.

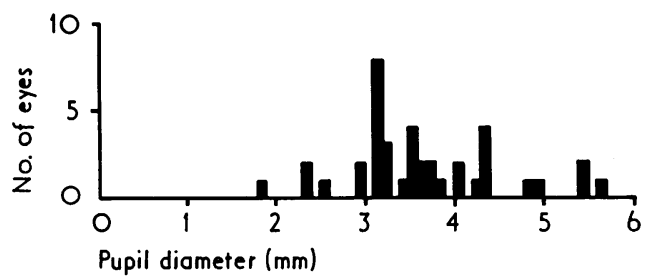

FIG. 6 Histogram of pupil diameters at which angle closure occurred

All six patients given Diamox developed closed-angle glaucoma.

(2) None of the 28 eyes from patients with narrow angles developed either angle closure or a raised intraocular pressure.

(3) The effect of thymoxamine 0.5 per cent. on a pupil dilated by phenylephrine io per cent. is shown in Fig. 7. All ten eyes behaved in the same manner and none developed angle-closure.

(4) During the miosis of the ten pupils dilated by cyclopentolate and thymoxamine three developed AC and a significant rise in intraocular pressure. One is illustrated in Fig. 8.
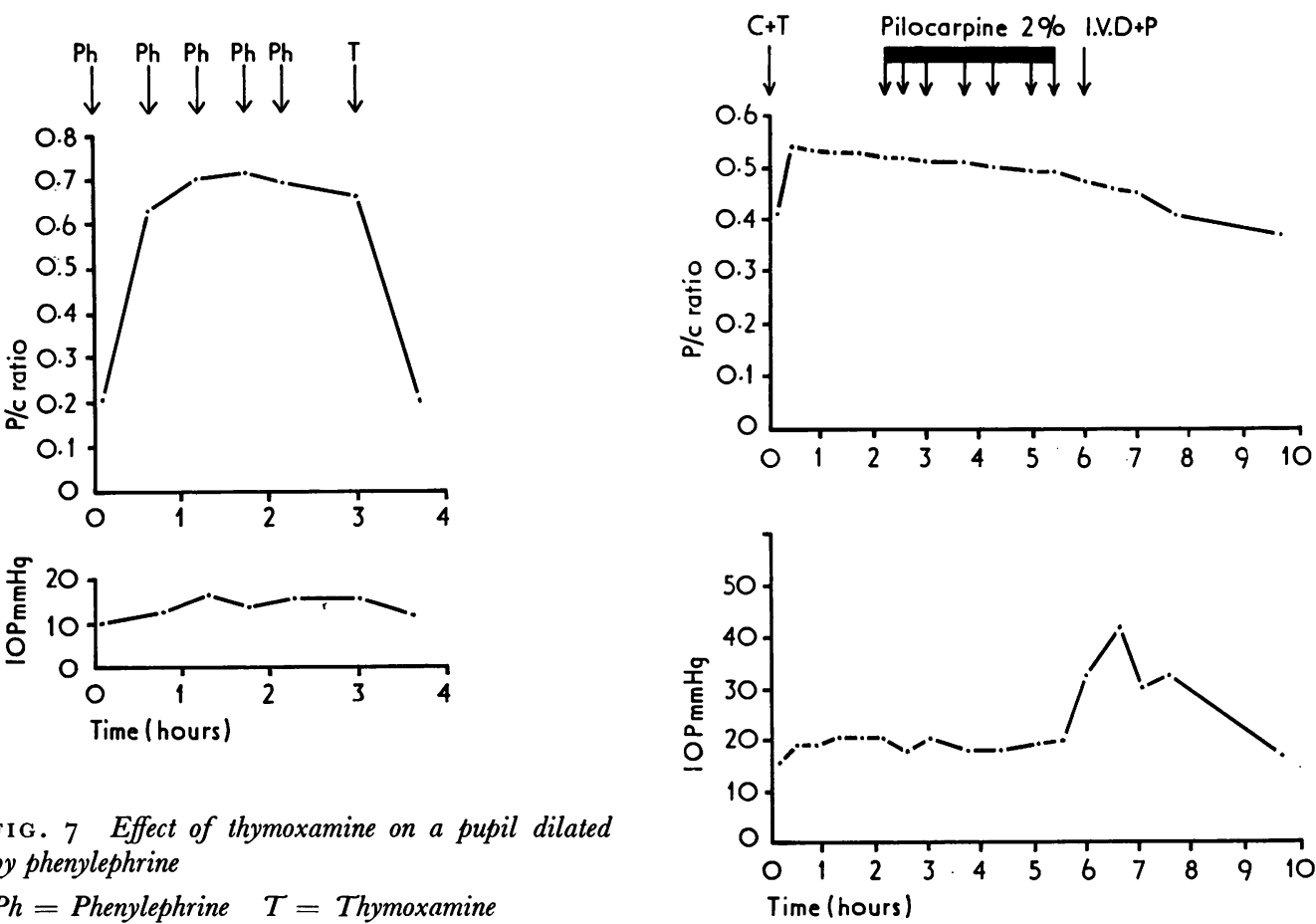

FIG. 7 Effect of thymoxamine on a pupil dilated by phenylephrine

$P h=$ Phenylephrine $T=$ Thymoxamine

FIG. 8 Effect of pilocarpine on a pupil dilated by cyclopentolate and thymoxamine. Closed-angle glaucoma was eventually produced

The mean value of the statistics from these three are summarized in Fig. 9 (opposite).

\section{Discussion}

In the discussion a $\mathrm{P} / \mathrm{G}$ ratio of say $0.3^{8}$ is regarded as a pupil diameter of $3.8 \mathrm{~mm}$.; the error involved is small and removes cumbersome conversions from the text. 


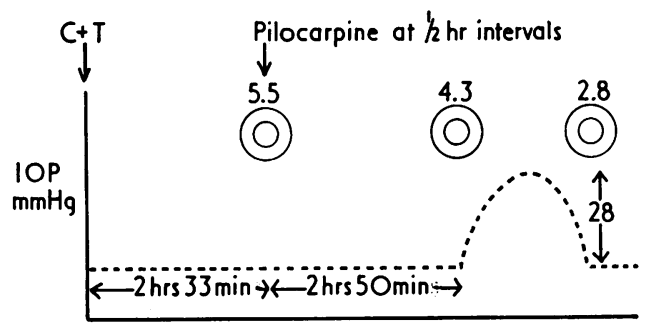

FIG. 9 Mean statistics of three eyes provoked to angle closure by pilocarpine after instillation of cyclopentolate and thymoxamine. The pupil diameter $(P / C$ ratio $\times 10)$ at the start of pilocarpine instillation, angle closure, and return to normal intraocular pressure are shown

$C=$ Cyclopentolate $T=$ Thymoxamine

Time

The simultaneous instillation of pilocarpine and phenylephrine precipitated closed-angle glaucoma in $2 \mathrm{I}$ eyes $(84$ per cent.). Of the $2 \mathrm{I}$, eighteen required no further pilocarpine and began to develop a rise in intraocular pressure after $53 \mathrm{~min}$. (Fig. I $a$ ) at a pupil diameter of $3.3 \mathrm{~mm}$. Pilocarpine exerts its maximal effect after approximately $55 \mathrm{~min}$. (DukeElder, I962) tailing off to zero at about $3 \mathrm{hrs}$. Phenylephrine has a similar temporal behaviour, and so AC occurred when both para- and sympathetic activity were at a maximum. In the three patients who required further pilocarpine the second dose was instilled $2 \mathrm{hrs}$ after the first-when para-sympathomimetic activity was waning. AG occurred $52 \mathrm{~min}$. later, again when both para- and sympathetic activity was at a maximum $($ Fig. $\mathrm{I} b)$. The change in pupil diameter between the second dose and AC was $0.9 \mathrm{~mm}$. From data previously published (Mapstone, I974a) the associated change in pbf is small and, therefore, although an increase in para-sympathetic activity would appear to be the precipitating event, it is unlikely to be due to a change in sphincter activity alone. Further iris bombé would-if anything-be less easy since the pupil was smaller.

This experiment, however, fails to distinguish between the relative contribution of sympathetic and para-sympathetic activity to AC. Precipitation by pilocarpine, followed after an interval by phenylephrine, does enable a distinction to be made since sympathetic activity can be maintained at a maximum and para-sympathetic allowed to fluctuate over a wide range. Of the 25 eyes so provoked, twenty ( 80 per cent.) developed closed-angle glaucoma, although twelve (6o per cent.) required a second dose of pilocarpine-a significant change from the previous group. Of the eight who required no further pilocarpine, AC occurred and intraocular pressure increased after I25 min. at a pupillary diameter of $3.9 \mathrm{~mm}$. (Fig. Ic). This pupillary diameter is larger than in the simultaneous group and reflects waning parasympathetic activity. It does, however, indicate that AC can occur in the presence of sub-maximal para-sympathetic activity. In the twelve patients who required additional pilocarpine, the second dose was instilled $160 \mathrm{~min}$. after the first, sympathetic activity was at a maximum and pupillary diameter $4.7 \mathrm{~mm}$. - indicating decreased para-sympathetic pupillary activity (Fig. Id). $5 \mathrm{I} \mathrm{min}$. later the angle had closed, intraocular pressure increased, and pupillary diameter had fallen to $4.2 \mathrm{~mm}$. The precipitating event was therefore a change in parasympathetic activity, but the change in pupil diameter implies an insignificant change in pbf and in the ability of the iris to become bombé, i.e. a para-sympathetic effect other than a change in pbf is the precipitating event.

Sympathetic activity was necessary since pilocarpine per se rarely produces an attack of closed-angle glaucoma. It was insufficient in the presence of sub-maximal para-sympathetic activity, and its presumed action is to move the pupil to a suitable position for iris bombé to occur, the latter event being para-sympathetically induced. The histogram (Fig. 6) shows that pupil diameter is not a critical factor but that the 3 to $4.5 \mathrm{~mm}$. pupillary range is the most common at the inception of $\mathrm{AC}$ - under the condition of these experiments. 
The absence of one attack of angle closure in the 24 eyes with narrow angles implies that whilst a specific anatomical configuration is necessary for the development of AC, it cannot by itself initiate an acute attack. This is predictable since anatomical parameters are relatively static dimensions, whereas AC is an acute phenomenon (chronic closedangle glaucoma excepted).

No angle closed during the miosis of pupils dilated by maximal sympathetic activity. This observation is at variance with well-established clinical and experimental data that phenylephrine - even in minute concentrations - can precipitate AC in susceptible eyes. However, the situations are not strictly comparable, as sympathetic activity was kept at a maximum until thymoxamine was instilled, and in the presence of $S$ block (Mapstone, I $974 \mathrm{~b}$ ) this is probably safe. The danger occurs when sympathetic activity wanes and the pupil slowly passes mid-dilatation. Thymoxamine rapidly constricts such a pupil (Mapstone, i 970) and does not allow it to remain long in the danger zone.

Cyclopentolate-thymoxamine dilated pupils have minimal para- and sympathetic activity, and such anterior segments do not exhibit AC (Mapstone, I974b); during miosis with pilocarpine three developed AC. Under the conditions of the experiments sympathetic activity was minimal, and at the time of AC pupillary diameter was $4.3 \mathrm{~mm}$. having miosed from a maximum diameter of $5.5 \mathrm{~mm}$. (Fig. 9). Pbf cannot have been large, but was none-the-less present; however, the degree of para-sympathetic tone in the sphincter does not necessarily reflect that within the ciliary muscle. The fact remains that returning parasympathetic activity, in the absence of sympathetic tone, can produce AC.

The evidence therefore indicates that the precipitation of $\mathrm{AC}$ depends primarily on para-sympathetic activity. The sympathetic plays a part-moving the pupil to a position such that para-sympathetic effects produce sufficient iris bombe to close the angle. However, in the various angle-closing situations investigated, pbf varied over a wide range. This being so, pbf is unlikely to be the most important factor that initiates AC-its presence is necessary but not sufficient.

Pilocarpine-induced para-sympathetic anterior segment activity affects mainly the sphincter muscle and ciliary body. Sphincter muscle-and hence pbf-variations have been described in this and preceding papers. Ciliary body effects include the following:

(a) Variations in lens position.

(b) Variations in lens shape.

(c) Change in aqueous inflow.

(d) Change in trabecular meshwork outflow.

(e) Change in uveoscleral outflow.

(a) An anterior lens displacement induced by para-sympathomimetic activity (Abramson, Franzen, and Coleman, 1972, 1973) would effectively increase pbf. A mean displacement of $0.19 \mathrm{~mm}$. (Abramson and others, 1973) cannot cause a substantial change. Further, Rosengren ( 1953) has shown anterior chamber depth to be a static dimension during acute closed-angle glaucoma; it is unlikely therefore that lens movement will be a precipitating event.

(b) A change in lens shape would theoretically alter pbf, but as an ageing lens has a relatively static shape (Abramson and others, I973) the increase in pbf would be negligible.

(c) Grant (195I), Becker and Friedenwald (I953), and Krill and Newell (I964) have demonstrated a reduction in intraocular pressure following the instillation of pilocarpine 
that cannot wholly be explained by a decrease in outflow resistance, and have postulated an effect on aqueous production. A priori a reduction in aqueous flow would be an unlikely precipitating event for angle closure and would if anything reduce the probability of its occurrence. Further, all six patients in this series who were given Diamox before provocation responded by developing closed-angle glaucoma. Aqueous production cannot therefore be a critical factor.

(d) The effect of pilocarpine on aqueous outflow via the trabecular meshwork is well documented (e.g. Bárány, 1962). The probable result of a sudden increase in outflow, in the presence of pupil block, would be to create a greater differential pressure between posterior and anterior chambers so that the iris would be actively "pulled" onto the trabeculum - a suggestion originally made by Shaffer ( 1956$)$.

(e) Bill ( $1965,1969,1970)$, Bill and Hellsing (1965), and Bill and Wålinder ( I966) have demonstrated the existence of a uveoscleral outflow mechanism in vervet and cynomolgus monkeys that is increased by ciliary muscle relaxation and prevented by its contraction. A similar mechanism has been demonstrated in man (Bill and Phillips, 197I). In the presence of pupil block, pilocarpine would decrease the exit of aqueous by this route and again tend to create a greater differential pressure between posterior and anterior chambers. Effectively, therefore, the iris would be "pushed" onto the trabeculum. This assumes that aqueous can emerge from the posterior chamber by a uveoscleral mechanism.

If, therefore-as appears likely-pilocarpine can precipitate AC, the two mechanisms are as in $d$ and $e$ above. This is explored in subsequent papers.

From the evidence detailed above, it is concluded that the event of angle closure is largely dependent upon para-sympathomimetic effects, and if para-sympathomimetic activity is increased in the presence of a mid-dilated pupil-as with the simultaneous instillation of pilocarpine and phenylephrine-then a high incidence of positive results is obtained. This method has been found clinically useful and is as follows:

At zero hours 2 per cent. pilocarpine and io per cent. phenylephrine are instilled and intraocular pressure measured. Phenylephrine is added at $\frac{1}{2}$-hrly intervals until intraocular pressure increases and the angle closes (it is usually unnecessary to perform gonioscopy, as the iris becomes apposed to the cornea on the corneal side of the limbus and the slit-beam alone will show the presence of closure: Van Herick and Shaffer, (1969). If after 2 hrs the angle remains open, then additional pilocarpine is instilled. As soon as intraocular pressure increases intravenous Diamox $500 \mathrm{mg}$. and pilocarpine 2 per cent. plus thymoxamine 0.5 per cent. are given-the drops immediately and at $\frac{1}{2}$-hrly intervals.

The relevance of these experiments to clinical primary closed-angle glaucoma is not immediately apparent, since combined maximal para- and sympathetic activity is a highly unphysiological state of affairs, representing the maximum autonomic stress that a susceptible anterior segment can undergo. It does indicate that closed-angle glaucoma is not a unitary disease but rather a syndrome with multiple aetiologies.

\section{Summary}

The event of angle-closure can occur in situations where the pupil-blocking force varies over a wide range; pupil block, whilst necessary for its development, is not the proximate cause. The precipitation of angle-closure depends primarily upon para-sympathetic anterior segment activity, with the sympathetic playing a subsidiary role. The parasympathetic mechanism involved is an increase in trabecular meshwork outflow.

A method of precipitating closed-angle glaucoma in susceptible eyes that produces 80 per cent. positive results is described. 
I should like to thank Miss E. Grogan for secretarial assistance, and Mr. R. McBride for help in preparing the diagrams.

\section{References}

abramson, D. H., franzen, L. A., and coleman, D. J., (1972) Arch. Ophthal. (Chicago), 87, 6r 5 (1973) Ibid., 89, 100

BÁRÁNY, E. H. (1962) Invest. Ophthal., 1, 712

BeGKer, B., and friedenwald, J. s. (I953) A.M.A. Arch. Ophthal., 50, 557

BILL, A. (I965) Invest. Ophthal., 4, $91 \mathrm{I}$

- (1969) Exp. Eye Res., 8, 284

- (1970) Ibid., ro, 31

- and Hellsing, K. (1965) Invest. Ophthal., 4, 920

- and PHILlips, c. I. (1971) Exp. Eye Res., 12, 275

- and WÅlinder, P. E. (I966) Invest. Ophthal., 5, i 70

DUKE-ELDER, s. (I962) In "System of Ophthalmology", vol. 7. Kimpton, London

Grant, w. M. (I95I) A.M.A. Arch. Ophthal., 46, I I 3

KRILl, A. E., and Newell, F. W. (I964) Amer. J. Ophthal., 57, 34

MAPSTONE, R. (1970) Brit. F. Ophthal., 54, 690

(I974a) Ibid., 58, 36

(1974b) Ibid., 58, 4 I

Rosengren, B. (1953) Amer. J. Ophthal., 36, 488

Shaffer, R. N. (1956) In "Glaucoma. Transactions of the First Conference, I955", ed. F. W.

Newell, p. I I. Josiah Macy Jr. Foundation, New York

VAN HERICK, W., and SHAFFer, R. N. (I969) In "Proceedings of the I South African International

Ophthalmological Symposium, I968”, ed. M. H. Luntz, p. I37. Butterworths, Durban 